\title{
S 633
}

.E6

Copy 1

\section{A D D R E S S}

DELIVERED BEFORE THE

\section{AGRICULTURAL SOCIETY}

or

KENT COUNTY, DELAWARE,

October 15, 1857.

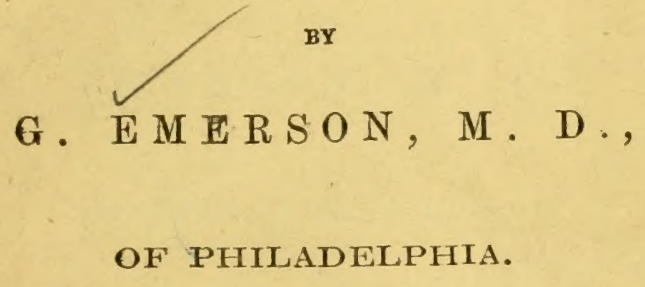

PUBLISHED BY ORDER OF THE SOCIETY.

P H ILA DEL P H I A :

NATIONAL MERCHANT PRINT, 1857. 



\title{
A D D R E S S
}

DELIVERED BRFORE THE

\section{AGRICULTURAL SOCIETY}

\author{
or
}

KENT COUNTY, DELAWARE,

October 15, 1857.

BY

G. EMER SON, M. D.,

OF PHILADELPHIA.

PUBLISHED BY ORDER OF THE SOCIETY.

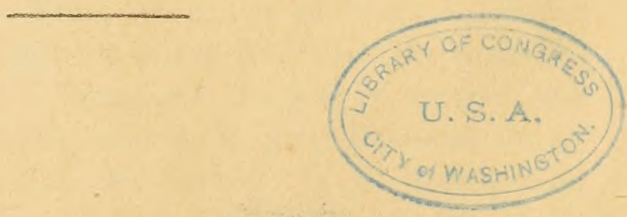

PHILA DELPIIA:

NATIONAI, MERCHANT PRINT, 1857. 



\section{A D D R E S S.}

\section{Gentlemen:-}

At very few days notice, and whilst my attention was greatly occupied by pressing engagements, I have accepted an invitation to deliver an address before the Agricultural Society of my native county. Had I consulted my own convenience or reputation, I should on such short notice have declined the task. But reflecting that I was not going among strangers whom it had often been my lot to address elsewhere, but among friends of my youth and maturity, who wouId kindly overlook any deficiencies arising from want of due time for preparation, I have not felt at liberty to refuse whatever contribution I may be able to make to your store of agricultural information.

Coming suddenly from my home in an immense commercial and manufacturing city, where a financial storm unexpectedly raised, is day after day wrecking the fortunes of the hitherto most prosperous, whilst those still holding out are hard pressed and painfully solicitous for their safety, I cannot but admire the appearance of serenity and security which prevails over this agricultural community. True, the prices of some important crops have declined, but still all is not lost, and the bountiful acres remain ever ready to furnish the means of support and independence. It was wittily said by a great financier on an occasion like the present, that the securest of all banks, were banks of earth, the most productive stocks those in the field, the best shares those of the plough.

At no very distant day things wore a dreary aspect in this now flourishing neighborhood, which, isolated, and far removed 
from the scenes of most activity and prosperity, then lay in a state of almost hopeless depression. It required the best part of two days to reach Philadelphia by the miserable mail stages and as many days to return, at a cost three or four times exceeding the present, to say nothing of the greater loss of time. Now, one can leave Philadelphia after a late breakfast, and without the least fatigue arrive here at the meridian hour. On looking around me I find on every side so many evidences of increased prosperity, exhibited in fine new dwellings, stores and churches, that I scarcely know where I am. And beautiful farms too, in places which were formerly lying out in unsightly commons, or covered by the original forests. Thanks to the spirit of enterprise that a few years since, led a few of the more hopeful and confident, first to venture on the establishment of a steamboat connection with the great market for the products of the soil, and which growing bolder has finally completed along the spine of the state, a railroad, the crowning triumph of our internal improvements, one that not only opens fresh fields and higher inducements for agricultural enterprize but for every other industrical pursuit. All honor to those whose intelligence, zeal and unremitting exertions have brought this most important enterprize ever attempted in the state to such a happy comsummation.

Let us take a slight glance at the position, soil, climate and adaptation of the section of country, thus as it were, newly regenerated. Kent is the middlemost and smallest of what in collonial times were known as the "Three Lower Counties on Delaware." Its surface presents a level alluvial, the eastern portion bordering on the bay shore known as the Necks, exhibiting a fine extent of clay loam heavily charged with dark vegetable organic matter, offering a soil of great agriculturnl value. In proceeding westward some two, four or five miles, the clay loam becomes gradually less tenacious, and more silicious. Sand however scarcely ever prevails in any part to such an extent as to make heavy roads, but is combined with clay in varied pro. portions, rendering it admirably adapted to agricultural and especially to horticultural purposes. I question whether any lands are to be fouud on the peninsula between the two great bays, or any where else, with soils so perfectly suited to the various objects of agriculture and fruit culture, especially to the perfect developement of the peach and the grape. 
In regard to climate this portion of the peninsula enjoys a most advantageous position, the winter season being far less austere than in other places westward in the same latitude, whilst summer heats are tempered by the influence of refreshing sea breezes, which for weeks rise in the morning and continue until evening. It is the highest point, so far as I can learn, where the mocking bird stays through the winter.

The former productiveness and prosperity of Kent County is indicated by numerous spacious brick mansions, once the imposing residences of good old families, many of which are still worthily represented in this audience. In conversation with persons living a little more northerly, I have been often surprised to discover the ignorance prevailing of the true condition of things in this county, and the peculiar advantages it possesses. I grant that those who come down by day on the newly opened line of railroad, this side of Black bird forest, may see very small corn stalks, and far too many of them. But such as approach by way of the old state road, especially if they diverge into the Necks, to the eastward, can look upon thousands of acres in high culture, producing large wheat fields averaging 25,30 and even more bushels to the acre, and extensive corn fields with 40 to 60 bushels per acre. The lover of the beautiful and majestic productions of nature, may stop and gaze almost with rapture upon the pride of the American forest, the Tulip poplar luxuriating in its favorite soil, often attaining the height of 150 and 200 feet, with diameters of 8 and 9 feet.

One of the most profitable topies which can be brought to the consideration of a rural audience on an occasion like the present, is the most ready means of improving exhausted soils and keeping up fertility.

All upland soils lose more or less of their original fertility, after cultivation, and we know that many parts of the old world once famed for their productiveness and teeming populations, have long since passed into sterility and desolation. Syria may be referred to as one example, and Sicily, the granary of old Rome, another. Even in our New World, many portions of the Atlantic states once distinguished for profitable husbandry, have become improvished below the point which requites labor. In 
such cases the soils have parted with some elements essential to the growth and developement of plants, and the most important of these has been ascertained to be phosphoric acid, which, combined chiefly with lime, abounds in the bones of animals. One of the most eminent french philosophers, M. Elie De Beaumont, member of the National Institute and Professor of the Royal School of Mines, has devoted himself to an investigation of the agricultural utility of phosphoric acid and its compounds, to the abstraction of which from the surface of the earth he ascribes that decay of powerful nations to which I have alluded. $\mathrm{He}$ has even gone into a profound calculation to show the vast amount of this fertilizing material that has been buried six feet under ground, in graves tenanted by the thousands of millions who have successively passed away since the days when the rude celts yielded the land to French cultivation and civilization. The grand result which he arrives at is that no less than two millions of tons of phosphate of lime, has during this period been drawn from the soil, converted into human bones and now lies beyond the reach of plants, lost to vegetation and the necessities of animal existence.

Colbert, he says, prophesied that France would perish from the destruction of her forests, an event which every one may conceive could have taken place, had it not been for her wealth in coal. In his time no one could comprehend how a great nation might perish for want of phosphorus in the soil. But this will come to pass if mineral resources fail to furnish elements which will administer to agricultural necessities, what coal does to the domestic wants and mechanical arts.

The admirable efficacy of animal bones to increase productiveness in soils has been known by the English farmers for a good many years past, and every part of the world has been ransacked to obtain them. Even the field of Waterloo and other scenes of human carnage are said to have contributed extensively to this traffic. Thousands of tons of bones-not however of human subjects-have been sent from Philadelphia alone, until within the last two or three years, when the recognition of their great value by our own farmers has so enhanced their price as nearly to prevent further exportations. 
Whilst plants during their growth and developement can obtain more or less ammonia from the atmosphere, they are dependent entirely upon the soil for the necessary supply of phosphoric acid. But the proportion of this last, even in highly productive land is so minute when compared with the more common ingredients of soils, that the efforts of chemists often fail to detect its presence. There is indeed little of what is called the best land that may not be highly berefitted by applications containing phosphoric acid.

Bones were first employed as manure crushed into coarse fragments or ground into dust, states in which they were very slowly soluble and comparatively inactive. Very recently Baron Liebig recommended dissolving them in a strong acid in order to effect their more complete subdivision through chemical agency, and thus enable them to exert at once their fuliest fertilizing action. Experiments founded on these views, made soon after their announcement in England, by Mr. Flemming, the Duke of Richmond, Messrs. Pusey and Morton, warranted them in making the strong declaration, that "this mode of preparing bones promised the most important saving ever held out in the use of manure," a promise which has been realized so that now in England, after years of experience, the preparation and use of super-phosphate of lime from bone-earth and mineral phosphates, has been fully recognized as "the great agricultural discovery of the age." The amount annually manufactured there and applied to crops may be imagined when I tell you that, of the very many engaged extensively in the business, one person alone, Mr. Lawes of Hertfordshire, makes annually more than 12,000 tons of super phosphate of lime.

Fortunately for the agricultural interests of the old world and those portions of our own country suffering from exhaustion, sources from which almost unlimited supplies of phosphoric acid can be obtained, have been discovered in the islands of many seas, chiefly tropical. But for this timely discovery the competition for bones, great as it is at present, would have driven up their price for agricultural purposes far above what we could afford to pay, on this side of the Atlantic.*

* To give some idea of the immense trade now carryiug on in concentrated fertilizers, supplying among other elements, that which $\mathrm{M}, \mathrm{De}$ Beaumont asserts 
The great advantages derived from this class of concentrated manures, lately introduced, and mainly dependent for their fertilizing effects upon phosphoric acid, are strikingly displayed in this county, where the first essays in this country were made, and where, I believe, a larger amount of them has been used, in proportion to the population, than in any section of similar limits in the United States. And what has been the result, after such heavy expenditures? Are the farmers any poorer. Or are they not vastly more prosperous and independent? The affirmative cannot be doubted for a moment, and I have often expressed the gratification felt in finding Kent County so much in advance of other places in the employment of concentrated fertilizers.*

Guano has been most liberally purchased until the price of Peruvian has reached a pitch almost past endurance, especially should the late decline in the prices of agricultural products continue. Besides, many people have been greatly disappointed in the enduring effects of guano, and even found that its repeated application to the same ground impaired fertility. Having had

to be necessary for national subsistance, I will make the following quotation from a recent number of Hunt's Merchant's Magazine :-

The important part which the guano trade is performing in the commerce of the world, and its influence upon shipping interests, is but imperfectly understood. Vessels carrying cargoes to our west Pacific coast, formerly were obliged to depend for return freights upon China and the East Indies alone ${ }^{\circ}$ Now they are directed to the Chinchas, which furnish cargoes at high rates, for foreign and American vessels, to a very large extent.

Nearly 400,000 tons of guano are required for Great Britain and Ireland, and 250,000 tons for the United States. Every sea is explored to obtain this valuable fertilizer.

The aggregate value of the different varieties now in the markets of the world cannot be less than $\$ 140,000,000$ per anuum. To the Peruvian government the revenue derived from her guano trade exceeds the amount from all her other sources of income-her mines of gold and silver, agriculture, ete.

This great trade is annually swelling into still greater magnitude, from the introduction of new varieties. The predominant ingredient of the Peruvian is ammonia, found almost exclusively in the rainless latitudes in which the Chincha islands are located; while those in which the phospha es prevail, are largely deposited on islands on the eastern side of our continent particularly in the Caribbean Sea, most of which are believed to be included inthe contract of the Philadelphia Guano Company. A very extensive market exists in Europe and in this country for this article. Farmers have discovered what had clearly been demonstrated by agricultural chemistry, that, without the application of mineral salts found in these guanoes, soils would soon become barren, and the presence of ammonia be of little avail. The improvished lands on our southern sea board are being resuscitated by its use.

* It has been estimated that in one single year, Kent County with a white population of about 17,000 has expended for concentrated fertilizers, chiefly guano, no less than $\$ 175,000$. Single farmers in the county have lately been using from 10 to 40 tons of super.phosphate annually upon their crops 
occasion for sereral years past to make use of 30 or 40 tons a year of some concentrated fertilizer, it of course became a matter of vital importance to my interests that what I procured at such heavy cost should prove remunerative. Tons of Perurian guano I had applied until, discouraged by its transient effects, I saw the necessity of employing some fertilizer in which phosphate of lime instead of being locked up through partial insolubility, as in guano and ground bones, was made soluble and immediately active, whilst the ammonia was fixed so as to be incapabic of flying away. These advantages I wished combined in an article of easy application, the cost of which would not exceed $\$ 5$ to $\$ 8$ per acre, a price no greater than sulfices in some places to pay the labor of hauling and spreading barn-yard manure. And this great desideratum I hare obtained by calling into requisition the slill of a practical chemist, by whom I am now supplied with the fertilizing properties of bone-earth inmediately soluble in rain water and consequently capable of exerting most prompt effects upon vegetation, combined with ammonia in a form rendering its escape and loss impossible.

Everybody linows what crushed or prowdered bones will do to benefit land. But then it requires some $\$ 15$ or $\$ 20$ worth of these per acre to accomplish less good than may be gained by the convenient application of a properly prepared super-phosphate of lime, costing not over one-third the money. By this improvement the way is open to the small as well as the rich farmer, the tenant as well as the owner, of immediately increasing the fertility of his land, so as no longer to waste his strength in the unprofitable tillage of inprovished and umproductive soil.

Bones have recently been offered to the farmer reduced to a finer state than that formerly obtained by grinding, and much more inviting in appearance through at an increasel cost. From their containing animal matter they have been reckoned by many superior even to gruano or the super-phospate of lime. It is however evident to persons well acquainted with the subject that such cannot be the case, since the phosphoric acid of the bones is in an insoluble state, and the amount of ethicient animal matter greatly reduced by the process to which they are axposed, namely, high steaming, through which means they are it is true, reduced to brittleness, admitting of fine pulverization, at 
the expense however of one-third of their efficient animal matter, the albunen acquiring from heat the hardness and insolubility of horn. The remaining portion of animal matter, amounting in fresh bones to about 22 per cent., is capable of furnishing about 4 per cent. of ammonia in the slate of a volatile carlionate. When put into the grround this volatile carbonate is constantly forming and escaping, with greater or less rapidity according to the warmth and moisture present, the process going on day and night as long as any animal matter remains. The only portion which plants can appropriate to their use is the little that may be washed down to their roots when it rains. Should rains not come before the decomposition ceases, the ammonia will of course all be dispersed into the atmosphere and lost.

I have devoted many years to the investigation of the subject of concentrated and artificial fertilizers, and do not wish you to receive my conclusions as mere opinions derived from curious studies, but as results of long experience in the open field and very extended observations. Farmers, I know, are given to boasting of their success. Whether I go too far in relating the results of my own operations may be easily ascertained by any of you who will take the trouble to visit my farms, near at hand. On one of these which has not yet been two years in my possession and was before desperately poor, the produce of the corn crop has been riaised from 10 or 12 , to 30 or 35 bushels per acre, all by the application of 300 to $400 \mathrm{lbs}$. per acre of a good super-phosuhate of lime. On other farms which have been much longer rimder improving operations, large fields will average 50 and 00 bushels per acre.*

\footnotetext{
* For my own satisfaction I have bad chemical analyses male of many of the fertilizers exteusively sold in tue Ppiladelphia and Balimore markets. Some of these, recommended by the most plausible puifs, have managed 10 gain a great reputation and exiensive sale; but though bearing the name of super-phosphate, I found them entirely destitute of soluble super phosphate, whilst otuers contained very small proportions, far short of what a good aricle should contain. And yet the most favorable representations were made of their riches, supported by certificates from chemists of high standing. Are not these gentlemen sometimes imposed upon by having good samples placed in their hands to analyze? The vender knows litile or notuing of the real value of what is put with bim to dispose of, and is generally ready to meet the views of those who want the cheapest articles. The farmer in order to get a fertilizer one or two dollars perton lower, will pass over a good one and throw away his money in the purchase of another which may not enable him to raise half as much produce as with the first. The damp state in which some articles are sold, amounting to 25 or 30 per cent. of water, often causes a loss of one ton in the
} 
In some few places I have certainly witnessed better effects: immediately following the application of Peruvian guano than were obtained from super-phosphate of lime. This has been the case where little or no vegetable mould remained in the ground, and in bottoms, and more especially swamp land. Such places are often so charged with acids derived from the decompusition of beds of fallen leaves or rank vegetable growth, that nothing but coarse weeds and briars will grow upon them. Before they can be profitably tilled in grain crops this cxcess of acidity must be corrected. Fresh or unleached ashes, when they can be obtained in sufficient quantity, will accomplish this object exceedingly well : so will treshly slaked lime. But both I believe are greatly inferior to Peruvian guano, the large amount of volatile ammonia in which, is probably seized upon by the acids, which are not only neutralized and rendered harmless to grain cross: but the new compounds of ammonia formed prove highly beneficial fertilizers. Within the past year I have met with a beautiful result of this lind. In a piece of black swamp land, Peruvian guano was applied at the rate of about $250 \mathrm{lbs}$. per acre. A small place was left without guano, which yielded literally no wheat at all, whilst that portion dressed with guano brought about 30 bushels per acre of the finest grain.

Although the necessity of phosphoric acid and ammonia for the restoration and continuation of fertility is so apparent, it is worth bearing in mind that fertilizers showing by chemical analyssis the largest proportion of them are not always those from which the most immeailate profits are derived. Thus, ground bones and imperfectly prepared super-phosphate of lime will often show a very large amount of phosphoric acid which may be locked up in a comparatively insoluble condition, requiring years to develop through gradual decay. So likewise a great amount of ammonia may exist, though in such a volatile state as to admit of its escape before it can be made available to crops. Its well known pungent and pervading smell, lite that arising from most animal manures, is an evidence of departine strength, and the stronger the smell the more rapid the waste.

purchase of three or four tons. Some manufacturers who would not be guilty of practicing wilful fraud, are incapable of making good articles. The desire to have a fertilizer of the best quality, bas led me to patrouize a manufacturer whose process is at all times open to my inspection. 
To those who have occasion to apply concentrated ferlilizers, uspecially the super-phosphate of lime, there is one recommendation I will make as of great importance; namely, where the supply of barn yard or other animal or vegetable manure is not sufficient to give a proper dressing to a whole field, not to apply what they may have by itself on a certain part of the field, but have it spread thinly, even if it does not afford one-half or onefourth of a good dressing, and make up the amount of a full dressing with the super-phosphate or other concentrated fertilizer. As a general rule mixtures of manures produce greater benefits than can be obtained from any one kind used alone.

All outlays made by farmers from which no adequate returns are received must be regarded not only as good money sunk by individuals, but as so much capital taken from the productive resources of the country. To say nothing of the many other causes of loss, such as ill-directed labor, inefficient tillage, etc. 1 will advert to one of far greater extent than is commonly believed, namely the misuse of lime. This is a subject which I uwelt upon, not long since when addressing, on an occasion like the present, the Agricultural Society of Chester County, Pennsylvania. I then said that if the Chester Co., agricultural society had the amount annually lost through the misapplication of lime within its own limits, it could afford to endow an agricultural college, and distribute princely premiums. With the view of making myself better understood I will premise that every substance applied to the soil either as an immediate fertilizer, ameliorator, or chemical corrective, in order to exert good effects promptly, must be capable of solution in rain water. Now, lime is only in a state to be promptly dissolved and carried into the ground for a limited time after it is slaked. Every one knows that it will not make good mortar or white-wash after long exposure to the air, such exposure rendering it insoluble in water. The most favorable state in which lime can be applied to land is immediately after slaking, and when in the finest powder. Then, it is readily dissolved by rain water and carried into the soil, like so much soluble super-posphate. Five bushels of lime applied thus I regard as capable of exerting better effects in most cases than 50 or even 100 bushels, spread after long exposure to the air, especially if it has been soaked by water and rendered lum- 
py. Indeed in this last condition, one very often met with, I regard lime as almost worthless, and unless applied on soils filled with acidity, little better than pebbles,

All estimates of the quantity of lime required for agricultural application must be made with strict reference to its condition. When it has been brought by sufficient atmospheric exposure to a state incapable of making white-wash or mortar, or into the chalky condition, the quantity required to produce good eflects must be greatly increased. In England where native chalk is abundant it is extensively used on land, 500 or 600 bushels being spread to the acre. Now, the sane rule applies to calcareous marle, and lime which after slaking has been inuch exposed to the atmosphere. Both are neither more or less than chalk, or carbonate of lime, a substance so partially soluble in water, that to produce good efiects immense quantities must be used. Some idea may be formed of the loss sustained from lime suffered to get into an effete and insoluble state, by viewing the mounds lying at landings and depots, where it is often left neglected for months before spreading.

Let us now suppose that land greatly reduced and incapable of producing enough barn yard manure to insure profitable tillage, has through the judicious application of lime, ashes, guani. or what I prefer in most cases, a good ammoniated super-phesphate of lime, been brought into a condition to produce goed grain crops, clover and other herbage, by which the ineans are furnished of supporting stock and making a supply of barn yarti manure. At this stage of improvement the farm should no longer mainly depend upon foreign supplies, but, if the manure madt: is properly taken care of, be able to sustain itself by its own resources. The immense amount of barn yard manure annually wasted is a subject of serious consideration. It is often washed away from the pound by drenching rains, and hence the great. advantage of deep beds of straw or other litter to absorb it. It left through summer in the pound to be applied to the wheat sown in autumn, more than half its fertilizing salts may be washed away, and its ammonia dissipated. Hence also the advantage, in our hot climate of keeping it sheltered from the weather, and putting out all winter-made manure on spring crops.

A few words, can I think, be profitably said in relation to cer- 
tain green crops, which may be introduced by our farmers with great advantage. I need not occupy the time of those so familiar with red clover in describing its many invaluable qualities as a forage crop and means of improving the soil. But in some lands, especially those of a sandy quality, red clover often disappoints the expectations of the farmer by dyeing out, sooner or later, in summer. Now, where this occurs there are other forage plants, which, from being capable of standing droughts, and even flourishing in them, and growing on land too poor to produce red clover-recommend themselves as substitutes, Among these is Lucerne, (medicago sativa) called in England Purple Medick Grass, or French Clover. It has been brought into the United States from South America under the various names of Alfafa, Chillian, and Brazillian Clover, leading to the belief of its being a native of the Southern Continent. But it was unquestionably introduced by the first settlers from southern Europe, where it has been cultivated as an indispensable forage crop since the days of the Romans. Although it succeeds well in the moist climate of England, it is evidently peculiarly adapted to the exigencies of drier climates, and more arid soils. When these are deep enough they need not be very rich in order to produce good crops of Lucerne, which may be kept good for many years by occasional top-dressings. A writer in one of our agricultural periodicals says, that from his experience he is convinced no other crop can at all compare with Lucerne for abundance and quality, and for cutting green and feeding in the yard to farm stock, or for making hay of the most fattening properties. Hogs fed or pastured upon lucerne require no other food, being often slaughtered in fine condition after feeding on it alone. He recommends sowing broadcast instead of in drill rows, as usually advised, the seed to be scattered thickly on clean and and well pulverized land, either in spring, summer or autumn, and without any other crop. The plants, if not choked by weeds, will soon cover the ground. An early cutting frequently repeated, gives lucerne a start over the weeds, and a slight harrowing after each mowing will enable it to keep the advantage.

Those who wish to see lucerne growing, may find a handsome lot in the neighboring town of Camden, on the premises of Hunn Jenkins, Esq. He sowed the seed broadcast with oats 
two years ago, and has mown several crops from it the present season. It should not be cut often until the roots attam a good size and depth. I am well satisfied that the more extensive introduction of this pasture and forage plant will prove of immense advantage to the agricultural resources of this country. The seed is now imported from France, and sells for about three times the price of common red clover seed, and like it, requires to be sown at the rate of ten or twelve pounds to the acre. Once set it does not want renewal for many years.

As very similar in its nature and good qualities to Lucerne, and adapted to soils unfavorable to clover, I would also invite attention to Sainfoin, the Bourgogne or Esparcette of the French farmers.

There is yet another green crop, which I think may be introduced into this section of country, so as to subserve important ends. I refer to the Cow Pea, now extensively cultivated in the southern states where the hot and dry summers so often kill out red clover. Although called peas, they are not round, but strictly beans of moderate size, affording food for man and beast. They will grow on land where clover cannot be raised, and when turned under in a green state greatly improve the soil. I last year received two varieties of the Cow Pea from Judge John R. Donnell, of Newbern, North Carolina, one of the largest farmers in that state-who in addition to his immense corn crops sometimes gathers 2500 bushels a year of these peas.

One of the varieties was of a uniform yellow color, and grew through the trying drought of 1856 with great luxuriance, producing slender pods nearly a foot long. But they matured imperfectly.

The second variety was a speckled pea, which has been more recently introduced into North Carolina. It grew well through the severest droughts, produced less foliage than the first lind, but more pods, shorter and filled with well matured seeds. Both varieties were planted in Little Creek Neck, about five miles east of this place, on missing cornhills, and some in drill rows.

This summer, in the first part of July, I had a portion of a field, intended for wheat, ploughed and sown broadcast, with the speckled peas. They grew luxuriantly, and when mown a few days since, (about the 9th of October), had well matured peas 
in many of the pods. It proved very difficult to cure and convert the stems, leaves and pods into hay, but this might in some degrec be owing to want of experience. The stubble and deep roots have been ploughed under, and next season will show the results. As they seem to defy the most trying droughts, they certainly merit the attention of farmers, especially such as cultivate the lighter and warmer soils, where the injury from dry weather is most severely felt.

Henry Burgwin, Esq., an extensive North Carolina farmer, who has devoted much attention to the subject of improvingr worn-out lands, has published interesting details of his process in the Patent Office Report for 1849-50. He says that by the use of peas followed by clover, he has succeded in improving land $s_{0}$ :educed as to yield only 7 or 10 bushels of corn, to 218 bushels per acre, and wheat from only 4 or 5 bushels to 10 arr? 12 bushels per acre.

The best way to begin the culture of any of the green crops I have recommended, is to lay down lots of moderate size, the results on which will make one acquainted with the nature and qualities of the plant, and show what advantages may be gained through its more extensive cultivation. It is often of the greatest importance, especially on small farms with limited or indifferent pasturage, to have lots laid down in some luxuriant-growing plants, such as clover, lucerne, or even corn sown broadcast. These can be cut from time to time and fed green to horses, cattle, and other stock, so as to keep them thriving and healthy, and be the means of saving a large amount of corn and oats.

For winter use there are certain root crops, the culture of which should be encouraged by liberal premiums offered by agricultural societies. I refer to the varieties of turnip, the sugar beet and carrot. Supplies of these will prove highly refreshing and useful for cattle, sheep, and even horses, whilst feeding on hay and other dry food during many months in winter and spring. For sheep-the most profitable of farm stock-rovt. crops are of the utmost importance as a part of their winter food

The culture of the sugar cane lately brought from China introduces a new object of profit to farmers, and the exhibition here of specimens of excellent syrups made in this neighborhood, with the beautiful granulated sugar made in the lower part of 


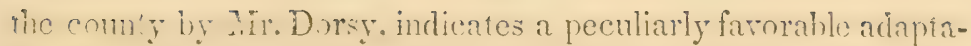
tion of the soil and climate of the county, to the production of saccharine matter in this new cane, readily reducible to the chrystalized form.

The eastern part of this county, washed by the waters of our noble lay , is one extended line of salt marsh, through which numerous creelis meander and carry navigation far into fast land. "The day may come when that spirit of enterprise which has so often gone beyond the most sanguine calculations, will succeed in reclaining and turning to a sricultural account the thousands of acres now almost valueless, and even worse than valueless, from the pests they send forth, to annoy the neighboring inhabitants, and worry and injure their cattle. Of the means by which so great and desirable a desideratum may be brought about, I have not time at present to speak, my object being merely to rcommend the introluction into these marsh lands of a species of grass which may render them, even in their present unstable state, highly valuable. I refer to what on the salt waters of Nerv Jersey and New York bears the name of Black Grass, (the Juncu i Gerardi of - Br tanists.)

On Long Island, where I have seen it growing on salt meadows, an ac $\mathbf{r}$ : well set in Black Grass is o ten regarded as of equal va'u? t) one in 'Timothy. Cattle wintered on hay made of it come out in spring in as fine condition as if they had been kept on clover hay. It is evident that the introduction of Black Grass on the $t^{\prime}$ o:isan is of acres now fumishing only bent and other coarse apologies for provender, would prove of great advantage to the agricultural resources of this county.

As a general rule farms devoted chiefly to grain crops are productive in roporio s to the herbage they are capable of yiclding; for on this depends their capacity to produce grain crops. The green pasturige sustains the stock necessary to convert the hay, straw and litter into farm-yard manure, and without stock the productiveness of a farm cannot be kept up long. I am a full believer in tic trite English agricultural proverb-which says-"Without the horn you cannot have corn."

When we reflect upon the necessity of agriculture to supply the most pressing wants of every living being, we find it not o.ly aflording sustenance to man and beast, but furnishing the 
basis upon which all industrial pursuits depend. If lands decline in fertility or productiveness, not only farmers sufier, but mer. chants, artizans and professional men find their means of support diminished. On the contrary, as farms and plantations are rendered more productive, every industrial pursuit receives a healthy impulse, and the evidences of prosperity are develnped on every hand. Sir Joseph Child, a sensible old English writer, says, quaintly, "Land and Trade are twins, and ever will wax and wane together. It cannot be ill with trade but lands must fall, nor ill with lands but trade must feel it." Let me add, that he who improves property in any locality, is not the sole recipient of the benefits of such improvement, as this surely extends itself to the possessions of his neighbor. Whatever selfish views a selfish man might entertain, were he a successful farmer, he could not serve his own interests without promoting those of his neighbor. What a comfortable reflection this, for the good man, whose delight is in doing what not only proves profitable to himself, but beneficial to others. A single intelligent improver may revolutionize a whole neighborhood, changing its povertystricken condition to productiveness and checrful prosperity.

Gentlomen, the great ends and aims of this and similar associations, is to advance all kinds of agricultural improvement, and render the labors of the farmer more productive. To accomplish this object, meetings are leld to discuss interesting topics, and exhibitions made annually or oftener, of the various products of the soils which engage the attention of the thrifty farmer. Along with these we find a collection of the best mechanical implements for aiding the farmer in sowing, tilling, harvesting, and threshing his various crops. Among other objects to be achieved by agricultural societies, I must not omit one of the most essential, namely, disperving the means of gathering useful information by the distribution of good books as premiums, or procuring them for circulating libraries.

The happy influences exerted upon agriculture by recent scientific researches, and the publication of good books adapted to an advanced state of education, are apparent almost every where, and I trust it may soon be said of our rural population what has been lately remarked by a writer in regard to the highly impruved state of agriculture existing at the present day in Scotland: 
"Forfunately," says this writer. "a higher style of education had begun to prevail amongst the farmer's sons, especially as regards physical science, and their minds were thus, in some msasure, prepared for understanding the novel and startling principles of agriculture propounded by Liebig. However distrustingly the old farmers viewed these new-fangled and theoretical notions, as they were pleased to term them, yet they had the good sense generally, to give their sons the opportunity of becoming acquainted with them; and as many of these young men threw themselves, heart and intellect, into the arena of experimental farming, they thus became the preceptors of their fathers, and will no doubt, in their turn, become the progenitors of a highlyeducated and scientific race of agriculturists. Liebig's theories have, undoubtedly, led to great changes and improvements in Scottish agriculture, by opening up a new field for practical experiment; and, although his work possesses a world-wide fame, yet nowhere has it given so general a stimulus to agriculture as in Scotland. His happy suggestion regarding the treatment of bones with sulphuric acid, and the formation of soluble phosphate of lime by such a combination, has opened up a new and exhaustless source of fertility, and established an entirely new trade in the country. His mineral thcory has suggested the profitable employment of many substances formerly looked upon as worthless; and the great importance he assigned to ammonia as a fertilizing agent, has turned the attention of the agricultural world at large, to the employment as manures, of many substances containing this important principle of vegetable life-thus opening up a new source of wealth and prosperity to the country. The introduction of guano into Britain has not only proved the correctness of Liebig's nitrogen theory, but it has also, by its practical effects, brought convietion to the mind of every intelligent farmer, that the researches of the chemist, instead of being visionary and useless, are of the very first importance in developing practical agriculture. It is due to the Scotch farmers to say, that no where have the suggestions of science been more successfully and generally put in practice than in Scotland. There is scarcely a furm to be found without chemical manures in some shape or other; and not unfrequently the expense for artificial manures alone, is equal to a half, or even three-fourths of the 
rent of the land. Cautious as the Scotch farmers are in all their transactions, they are no sooner convinced of the propriety of an improvement than they bring the whole force of their industry, skill, and available capital to bear upon its development; and should the latter necessary item be inadequate, they hesitate not to borrow, nor the manure dealers and money dealers to give credit, or to lend upon the faith of a successful result."-(Morton's Encyclopadia.)

In concluding I will remark, that in coming among you to-day it was with no view of indulging in declamation or speculations more amusing than profitable. Nor have I sought to tickle the ears of the more learned portion of my audience by erudite allusions to agricultural rules, and maxims to be culled from the pages left us by Cato, Columella, and other model farmers of the classic ages. My main object has been to invite your attention to subjects calculated to render our farmers more in elligent and our farms more productive. Where scientific topics have been dwelt upon, I have used the plainest language, so as to make mys lf $\mathbf{u}$ iderstood by every one present, and I trust that I have succee'e I in impressing upon the minds of some of you, views and suggestions which may be turned, sooner or later, to profitable account. 


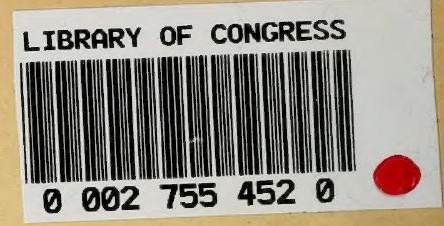

